\title{
Migração Intra-Abdominal de Sistema Intrauterino Após Perfuração Uterina
}

\section{Abdominal Migration of an Intrauterine Device Following Uterine Perforation}

Teresa Maria Sousa1*, Helga Martins²

PALAVRAS-CHAVE: Migração de Dispositivo Intrauterino; Perfuração Uterina

KEYWORDS: Intrauterine Device Migration; Uterine Perforation

Mulher de 37 anos, 2 gesta, 2 para (G2P2), sem antecedentes de relevo, colocou um sistema intrauterino (SIU) em consulta de ginecologia, dois meses após o segundo parto, em 2017. Foi realizada uma ecografia ginecológica imediatamente após a sua colocação, que assegurou o correto posicionamento do SIU.

A doente engravidou no ano seguinte à colocação do dispositivo. Nas ecografias obstétricas não foi possível identificar o SIU e assumiu-se que o mesmo teria sido expulso. A gravidez, sem intercorrências, foi acompanhada pela médica de família e em consulta de obstetrícia. O recém-nascido nasceu com 38 semanas, por parto eutócico, em 2019.
Em 2020, a doente foi referenciada pela médica de família a consulta de ginecologia para contraceção definitiva. $\mathrm{Na}$ consulta, foram solicitadas radiografias abdominal e pélvica, que revelaram um corpo estranho com a forma de "T" no quadrante superior direito do abdómen (Fig. 1), identificado como o SIU colocado dois anos antes.

Foi realizada cirurgia laparoscópica para remoção do dispositivo e salpingectomia bilateral, durante a qual se constatou que o SIU estava ancorado no mesocólon transverso. Foi pedida colaboração da Cirurgia Geral, que confirmou a integridade da parede do cólon transverso. Ambas as intervenções decorreram sem intercorrências.

\footnotetext{
1. Médica Interna de Formação Específica em Medicina Geral e Familiar, Unidade de Saúde Familiar Santa Clara, Agrupamento de Centros de Saúde Grande Porto IV - Póvoa de Varzim/Vila do Conde, Portugal. 2. Enfermeira especialista em Saúde Materna, Unidade de Saúde Familiar Santa Clara, Agrupamento de Centros de Saúde Grande Porto IV - Póvoa de Varzim/Vila do Conde, Portugal. 


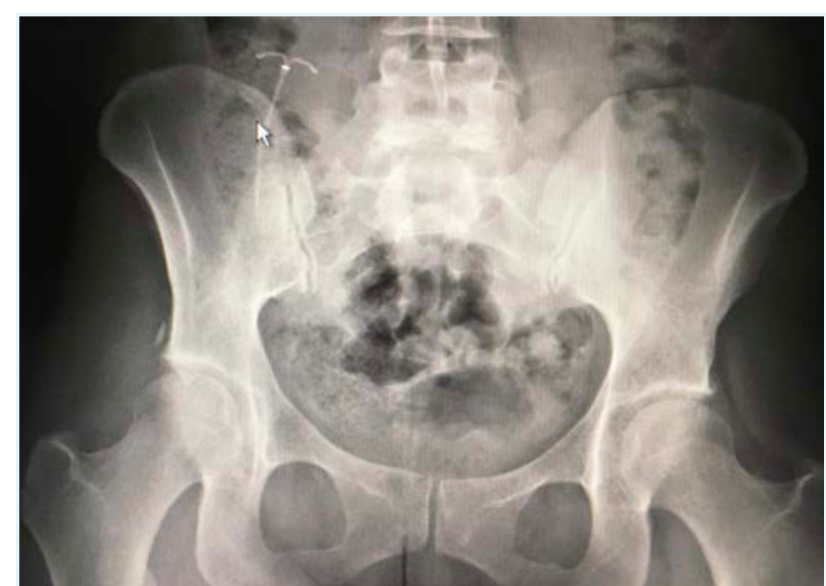

FIGURA 1. Sistema intrauterino localizado no quadrante superior direito do abdómen.

Os contracetivos intrauterinos apresentam elevada efetividade e segurança. A perfuração uterina é rara (0,06\% a $0,16 \%$ ) e obriga à remoção cirúrgica do dispositivo. ${ }^{1}$ Trata-se da complicação mais grave, que pode ser assintomática, causar dor abdominal, febre, ou hemorragia uterina. ${ }^{2}$ Em 15\% dos casos, podem ocorrer complicações em órgãos adjacentes. $\bigcirc$ cólon é frequentemente o mais afetado. ${ }^{3}$

A gravidez após colocação do SIU deve fazer suspeitar de perfuração uterina. ${ }^{2} \mathrm{O}$ diagnóstico deve ser realizado por ecografia, ou tomografia computorizada (após o parto). Em caso de migração e na ausência de comorbilidades, está recomendada a sua remoção para evitar complicações, nomeadamente a lesão de órgãos adjacentes, ou a formação de aderências. A abordagem cirúrgica deve ser planeada pela equipa médica, atendendo à localização do dispositivo. ${ }^{3}$

\section{RESPONSABILIDADES ÉTICAS}

CONFLITOS DE INTERESSE: Os autores declaram a inexistência de conflitos de interesse na realização do presente trabalho.

FONTES DE FINANCIAMENTO: Não existiram fontes externas de financiamento para a realização deste artigo.

CONFIDENCIALIDADE DOS DADOS: Os autores declaram ter seguido os protocolos da sua instituição acerca da publicação dos dados de doentes.

CONSENTIMENTO: Consentimento do doente para publicação obtido.

PROVENIÊNCIA E REVISÃO POR PARES: Não comissionado; revisão externa por pares.

\section{ETHICAL DISCLOSURES}

CONFLICTS OF INTEREST: The authors have no conflicts of interest to declare.

FINANCING SUPPORT: This work has not received any contribution, grant or scholarship.

CONFIDENTIALITY OF DATA: The authors declare that they have followed the protocols of their work center on the publication of data from patients.

PATIENT CONSENT: Consent for publication was obtained.

PROVENANCE AND PEER REVIEW: Not commissioned; externally peer reviewed.

\section{REFERÊNCIAS}

1. Pacheco A, Costa AR, Lanhoso A, Santos AT, Rodrigues C Rebelo C et al. Consensos sobre contraceção 2020 [e-book]. SPDC, SPG e SPMR; 2020 [accessed 2021 Mar 3]. Available: https://www.spdc.pt/images/SPDC_Consensos_2020 27Nov_Final_web_versao_livro_digital.pdf.

2. Mederos R, Humaran L, Minervini D. Surgical removal of an intrauterine device perforating the sigmoid colon: A case report. Int J Surg. 2008; 6:e60-62. doi: 10.1016/j.jijsu.2007.02.006.

3. Aliukonis V, Lasinskas M, Pilvelis A, Gradauskas A. Intrauterine device migration into the lumen of large bowel: A case report. Int J Surg Case Rep. 2020; 72:306-8. doi: 10.1016/j. ijscr.2020.06.011. 